\title{
Heats of Combustion and Formation of Cellulose and Nitrocellulose (Cellulose Nitrate)
}

\author{
By Ralph S. Jessup and Edward J. Prosen
}

\begin{abstract}
This paper gives the results of bomb calorimetric measurements of heats of combustion at $30^{\circ} \mathrm{C}$ of one sample of cellulose and four samples of nitrocellulose from cotton linters, and of one sample of cellulose and four samples of nitrocellulose from wood pulp. The results have been combined with values for the heats of formation of carbon dioxide and water to obtain values of heats of formation of the celluloses and nitrocelluloses. Empirical equations are given expressing heat of combustion and heat of formation of the nitrocelluloses as functions of nitrogen content.
\end{abstract}

\section{Introduction}

The work described in this paper was done at the request of the National Defense Research Committee, and the results were originally reported in their Armor and Ordnance Report No. A-285 (OSRD No. 3932).

The data presented in this paper differ from those given in the above report in the following respects: (1) the results are now expressed in terms of the absolute joule instead of the international joule as the fundamental energy unit; (2) the results have been reduced to the basis that all gases involved in the reactions discussed are in the thermodynamic state of unit fugacity instead of the state of the real gases at atmospheric pressure.

\section{Materials}

The materials whose heats of combustion have been determined were made available to the National Bureau of Standards through arrangements made by the National Defense Research Committee with the Office of the Chief of Ordnance, War Department.

The lots of cellulose from cotton linters and wood pulp were obtained from the Hercules Powder Co., Radford Ordnance Works, Radford, Va. For the nitrocellulose, the manufacturer, material nitrated, and the nitrogen contents were as follows:

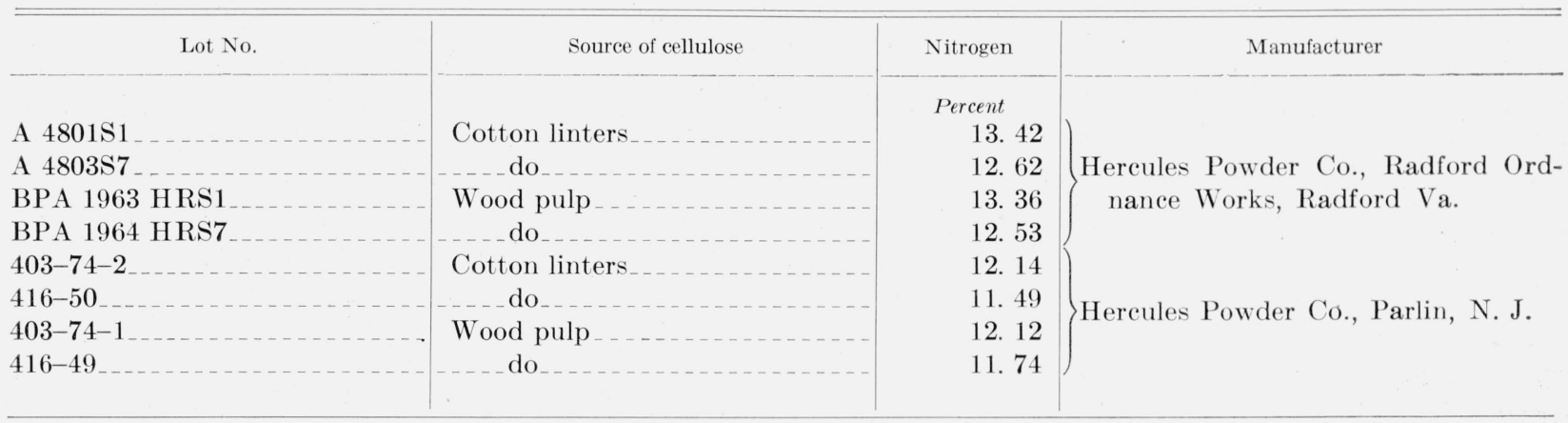

The analyses for nitrogen were made by the Hercules Powder Co. The samples of cellulose and nitrocellulose were regular plant samples. Because of the urgent need for the data, and as the heats of combustion of the actual plant samples were desired, no attempt was made to purify the samples further. 


\section{Preparation and Weighing of Samples}

The following procedure of preparation and weighing of the samples was followed. A batch of cellulose or nitrocellulose sufficiently large to serve for all the experiments on that sample was placed in a desiccator, which was evacuated until the material seemed dry and fluffy. Then portions about 10 percent larger than the amount needed for an experiment, about $2 \mathrm{~g}$, were roughly weighed out and placed in separate beakers. These portions were then wetted with distilled water and were compressed into tight pellets in a pellet press. The pellets then contained approximately 20 to 30 percent of water. These pellets were placed in separate weighing bottles having ground-glass necks and evacuated in a desiccator for about 3 to $8 \mathrm{hr}$. The bottles were then placed in an oven, kept at $100^{\circ} \mathrm{C}$ for $1 \mathrm{hr}$, cooled in a desiccator, stoppered with their ground-glass stoppers, and weighed against a tare (an empty weighing bottle of the same size). They were again placed in the oven at $100^{\circ} \mathrm{C}$ for intervals of $1 / 2 \mathrm{hr}$ until constant weight (within about $0.1 \mathrm{mg}$ ) was obtained. This was usually reached within about $2 \mathrm{hr}$ in the oven at $100^{\circ} \mathrm{C}$. About 10 percent of water, an amount that was found to produce the best conditions for burning the samples in the bomb, was added to the pellets, and the pellets were transferred from the weighing bottles to the platinum crucible in which they were to be burned. The weighing bottles, together with any particles of sample left in them, were put in the oven at $100^{\circ} \mathrm{C}$ for $1 \mathrm{hr}$ and reweighed against the tare. From these weighings the weight of dry sample was obtained.

All weights were corrected to the vacuum basis using the factor 1.00080 , obtained by assuming a value of $1.25 \mathrm{~g} / \mathrm{ml}$ for the density of dry cellulose and nitrocellulose.

\section{Apparatus and Method for Measure- ments of Heats of Combustion}

Measurements of heats of combustion were made by burning weighed samples of the material in oxygen in a constant-volume bomb that was part of a calorimetric system described elsewhere $[1,2,3] .{ }^{1}$ The bomb was made of a corrosionresistant alloy (illium) and had a capacity of

\footnotetext{
1 Figures in brackets indicate the literature references at the end of this paper.
}

0.380 liter. Two types of experiments were made. In one of these a measured quantity of energy was supplied to the calorimetric system, and the resulting rise in temperature was observed. In the other type of experiment a weighed sample of cellulose, or nitrocellulose, was burned in the bomb, the resulting rise in temperature was observed, and the mass of carbon dioxide formed was determined. The first type of experiment gives the energy equivalent (effective heat capacity) of the calorimetric system, and when the energy equivalent is known, the temperature rise in the second type of experiment is a measure of the heat produced by combustion $[4,5]$. For each experiment the mass of the dry sample of material burned, the mass of carbon dioxide formed in combustion in the bomb, and the mass of carbon dioxide formed in subsequent oxidation of gaseous products of incomplete combustion were determined. The mass of carbon dioxide formed by oxidation of the products of combustion was usually 0.01 or 0.02 percent of the mass formed in combustion in the bomb. Correction for incomplete combustion was made on the assumption that the only product of the incomplete combustion was carbon monoxide. The details of the methods used have been described elsewhere [3, 6].

In connection with the correction for the heat of formation of nitric acid in the bomb, the question arose as to whether some nitrous acid might also be formed, especially when the nitrocelluloses were burned in the bomb. To answer this question, tests for nitrous acid were made by W. S. Clabaugh $^{2}$ on the washings from the bomb after each of four combustions, two of benzoic acid and two of nitrocellulose. The air initially in the bomb was flushed out with oxygen before burning the two samples of nitrocellulose and before burning one of the samples of benzoic acid but was not flushed out in the case of the second sample of benzoic acid. The amount of nitric acid formed in the second combustion of benzoic acid was, therefore, several times that formed in the first. The amount of nitrous acid found did not exceed 0.5 percent of the total acid formed in any of these experiments. The error introduced into the results of heat of combustion measurements by assuming all the acid to be nitric acid is entirely negligible.

2 Chemistry Division of the National Bureau of Standards. 


\section{Calibration of Calorimeter}

The energy equivalent of the calorimeter for the temperature interval $28.5^{\circ}$ to $30^{\circ} \mathrm{C}$ was determined by burning NBS Standard Sample $39 \mathrm{f}$ of benzoic acid in the bomb, using the value 26433.8 absolute joules per gram mass (weight in vacuum), recently obtained in this laboratory $[3,9,10]$, for the heat of combustion of this material under the conditions of the standard bomb process at $25^{\circ} \mathrm{C}$. Appropriate corrections were made to take account of differences between the actual and standard bomb processes. The results of these calibration experiments are as follows: Series I, five experiments, energy equivalent $13862.6 \pm 2.1$ (standard deviation of mean) joules per deg C; Series II, six experiments, energy equivalent $13833.9 \pm 1.2(\mathrm{sdm})$ joules per $\operatorname{deg} \mathrm{C}$.

These values of energy equivalent are for the calorimeter containing the same mass of water as in the experiments on the nitrocelluloses, and with the bomb containing $1 \mathrm{~g}$ of water and oxygen under a pressure of $30 \mathrm{~atm}$ at $30^{\circ} \mathrm{C}$. In the measurements on the nitrocelluloses the values used for the energy equivalent differed from the mean values given above by two small corrections, one for the heat capacity of the charge of nitrocellulose and one for the heat capacity of the oxygen in the bomb in excess of that required to fill it to $30 \mathrm{~atm}$ at $30^{\circ} \mathrm{C}$.

The mean value of the energy equivalent obtained in Series I was used in calculating the results of measurements on the samples of nitrocellulose made from cotton linters and containing 11.49 percent and 12.14 percent of nitrogen. After the measurements on these samples were completed, the insulation of the firing electrode in the bomb failed, and the necessary repairs involved some change in the heat capacity of the bomb. The calorimeter was therefore recalibrated with the repaired bomb. The calibration experiments of the second series were made under the same conditions as those of the first, except that the calorimeter contained a smaller amount of water in the second series. The mean value of energy equivalent obtained in Series II was used in calculating the results of all measurements of heat of combustion, except those on the two samples of nitrocellulose just mentioned.

\section{Calorimetric Experiments on Cellulose and Nitrocellulose}

\section{Measurements of Heat of Wetting}

Since the samples were wet when ignited in the bomb, the observed heat produced by combustion of each sample was lower than that for the dry sample by an amount equal to the heat of wetting of the dry sample with the amount of water added to it. In order to obtain data for correcting the observed heats of combustion for this effect, measurements were made of the heats of wetting of the various materials.

The method used was similar to that described by Katz [7]. Samples of 2 to $5 \mathrm{~g}$ of each cellulose and nitrocellulose were placed in weighed glass tubes of about $12-\mathrm{mm}$ inside diameter, one end of which was drawn down to a fine capillary and sealed. The samples were then dried in vacuum (residual pressure less than $10^{-4} \mathrm{~mm}$ of mercury) until no water could be detected with the McLeod gage after the vacuum pump had been shut off for several hours. Dry air was then admitted to the vacuum space, and the tubes were removed, corked immediately, and weighed.

To determine the heat of complete wetting, a tube containing dry material was immersed in the water of a calorimeter with the sealed end down and the open end projecting 2 or $3 \mathrm{~cm}$ above the top of the calorimeter jacket. The top of the sample of material in the tube was $6 \mathrm{~cm}$ or more below the surface of the water in the calorimeter. The temperature of the water in the calorimeter was slightly lower than that of the jacket, so that there was no heat transfer by evaporation of water from the calorimeter and condensation on the jacket. After sufficient time had elapsed for the attainment of a steady state, a series of readings of calorimeter temperature and corresponding time was made. The fine capillary at the bottom of the glass tube was then broken by pressing it against the bottom of the calorimeter vessel, permitting water to rise in the tube and wet the material contained therein. Readings of time and temperature were continued for about $10 \mathrm{~min}$ after the rate of temperature change had become constant. Similar measurements were made on samples to which small known amounts of water had been added after drying and weighing. 
The results of the measurements of heat of wetting of the completely dry materials are given in table 1, together with values calculated for the nitrocelluloses from the empirical equation:

$$
Q=93.20-671 f,(0.115 \leqq f \leqq 0.135),
$$

where $?$ is heat of wetting in joules per gram, and $f$ is the mass fraction of nitrogen in the sample.

TABLE 1. Values for heats of wetting of samples of dry cellulose and nitrocellulose

\begin{tabular}{|c|c|c|c|c|}
\hline \multirow{2}{*}{ Source of cellulose } & \multirow{2}{*}{$\begin{array}{l}\text { Nitrogen } \\
\text { content }\end{array}$} & \multicolumn{2}{|c|}{ Heat of wetting } & \multirow{2}{*}{$\begin{array}{c}\text { Observed } \\
\text { minus } \\
\text { calcu- } \\
\text { lated }\end{array}$} \\
\hline & & Observed & $\begin{array}{l}\text { Calcu- } \\
\text { lated }\end{array}$ & \\
\hline & Percent & $j / g$ & $j / g$ & $j / g$ \\
\hline Cotton linters & 0.00 & 47.7 & & - \\
\hline Do_....... & .00 & 45. 9 & & \\
\hline Wood pulp $\ldots$ & .00 & 59.3 & & - - \\
\hline Do & .00 & 58.6 & & - \\
\hline Cotton linters & 11.49 & 16.5 & 16.1 & +0.4 \\
\hline Do & 11.49 & 16. 6 & 16. 1 & +.5 \\
\hline Do & 12.14 & 11. 7 & 11. 7 & .0 \\
\hline Do_.... & 12.62 & 8.5 & 8.5 & .0 \\
\hline Do $\ldots . . .$. & 13.42 & 3.8 & 3.2 & +.6 \\
\hline Wood pulp... & 11.74 & 14.9 & 14. 4 & +.5 \\
\hline Do.......... & 11. 74 & 13. 7 & 14.4 & -.7 \\
\hline Do ......... & 12.12 & 11. 2 & 11.9 & -.7 \\
\hline Do $\ldots \ldots$ & 12. 53 & 8.7 & 9.1 & -.4 \\
\hline - & 13.36 & 3.4 & 3.6 & -.2 \\
\hline
\end{tabular}

The results of measurements on samples containing small amounts of water are shown graphically in figure 1, where the abscissa is the mass of water per gram of dry material, and the ordinate is the difference between the heats of wetting of the dry and wet materials expressed as a fraction of the heat of wetting of the dry material. The solid curve in figure 1 represents data calculated from Katz's [7] equation for cellulose. The dashed curve is drawn through the points representing the experimental data obtained in this investigation.

\section{Results of Measurements of Heats of Combustion}

The results of the measurements of heats of combustion at $30^{\circ} \mathrm{C}$ are summarized in table 2 . The observed values of $-\Delta U_{B}$, the heat of combustion under the conditions of the bomb process, were corrected for heat of wetting, and reduced, in accordance with the procedure outlined by Washburn [8], to the corresponding values of $-\Delta U_{c}^{\circ}$, the decrease in internal energy accompanying the combustion reaction when each of the gaseous reactants and products is in its thermodynamic standard state of unit fugacity at $30^{\circ} \mathrm{C}$. The correction for heat of wetting was made on the basis of the observed value for heat of wetting of the dry material, and the data represented by the dashed curve of figure 1 .

In column 4 of table 2 are given values of the ratio of carbon dioxide formed in combustion in the bomb and in oxidation of products of incomplete combustion to that calculated from the masses of dry samples, based on the assumption that they were pure cellulose or nitrocellulose represented by the formula $\mathrm{C}_{6} \mathrm{H}_{10-x} \mathrm{O}_{5}\left(\mathrm{NO}_{2}\right)_{x}$. If $f$ is the mass fraction of nitrogen in the sample and $m$ the mass of sample burned, then the calculated mass of carbon dioxide was taken as (1.62859 $-5.23177 f) \mathrm{m}$. The values of atomic weights used in this and other calculations connected with this report are $\mathrm{O}=16.000, \mathrm{C}=12.010, \mathrm{H}=1.0080$, and $\mathrm{N}=14.008$.

\section{Further results derivable from experimental data}

It will be seen from table 2 that the average values of the ratio (carbon dioxide formed : carbon dioxide calculated) are less than unity by amounts ranging from 0.4 to 0.9 percent, indicating that the samples probably contained at least the corresponding amounts of impurity. If it is assumed

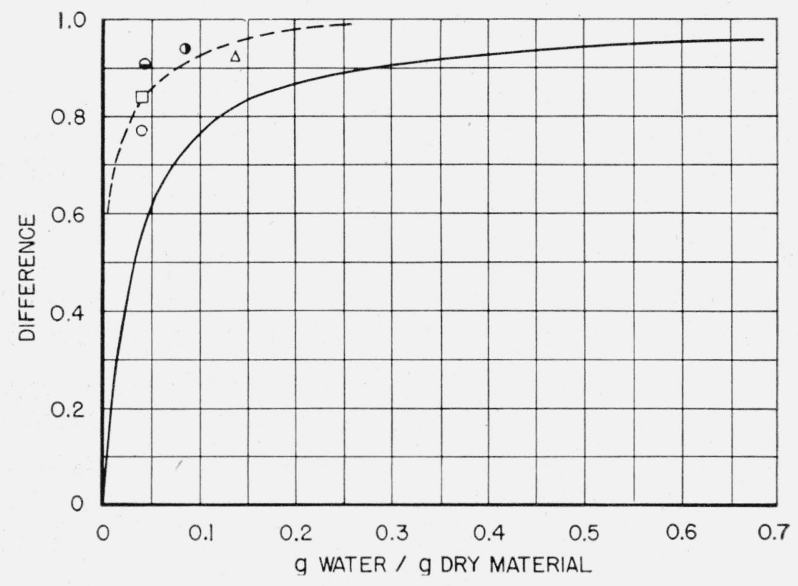

FIGURE 1. Results of measurements of heat of wetting for samples containing small amounts of water.

Abscissa, grams of water per gram of dry material. Ordinate, difference between heats of wetting of dry and wet materials expressed as a fraction of the heat of wetting of the dry material. Solid curve, Katz's da ta on cellulose. Dotted curve drawn to represent data obtained in present work. $\triangle$, Cellulose from cotton linters; $\bigcirc$, nitrocellulose from wood pulp, 11.74 percent nitrogen; $\square$, nitrocellulose from wood pulp, 12.12 percent nitrogen; $\mathbf{D}$, nitrocellulose from cotton linters, 11.49 percent nitrogen; $\ominus$, nitrocellulose from cotton linters, 12.14 percent nitrogen. 
TABLE 2. Experimental data on the heats of combustion a

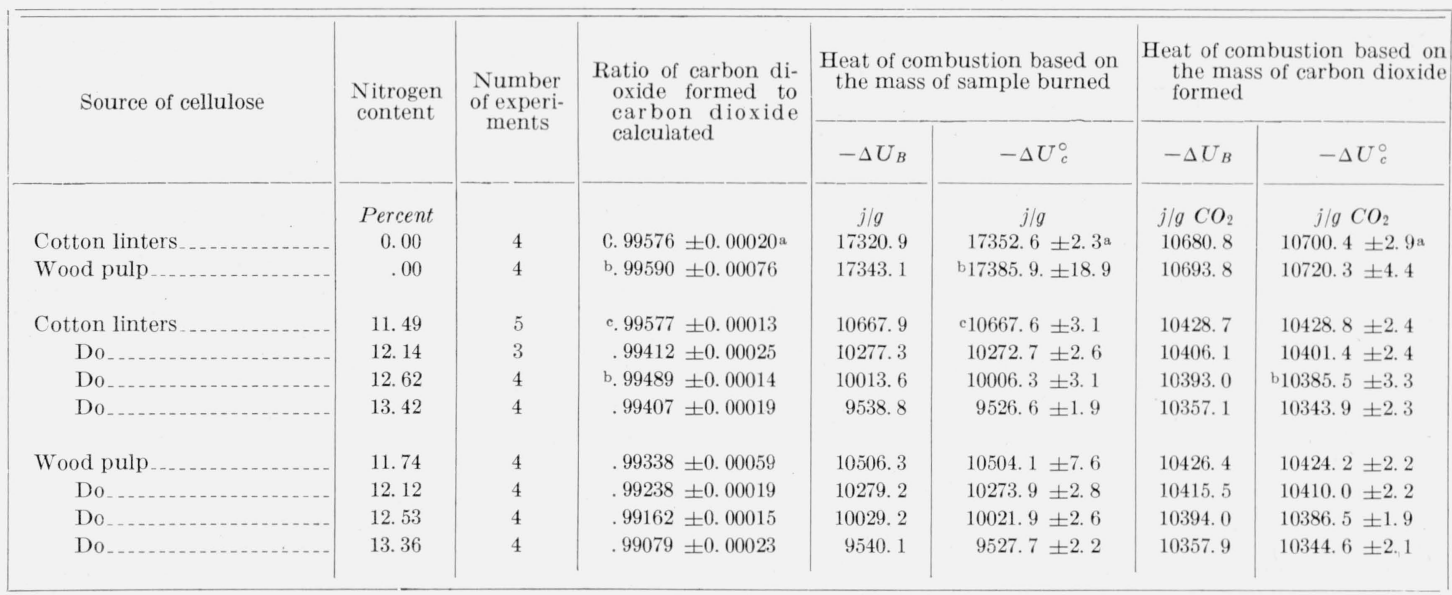

a The values following the \pm sign in this table are the standard deviations of the mean.

b Mean of three experiments.

c Mean of two experiments.

that all the impurity in the samples was inert material that did not enter into the combustion reaction in any way, then the values given in table 2 based on the mass of carbon dioxide formed should be the heats of combustion of pure cellulose and pure nitrocellulose. Under this assumption. however, the values of the nitrogen contents must be adjusted, due to the fact that the nitrogen content of a nitrocellulose containing inert impurity is higher than that reported for the impure sample. If we let $R$ be the ratio (carbon dioxide formed : carbon dioxide calculated) (see table 2), $f$ be the mass fraction of nitrogen as reported (see table 2 ), and $i$ gram be the amount of impurity per $(1-i)$ gram of $\mathrm{C}_{6} \mathrm{H}_{10-x} \mathrm{O}_{5}\left(\mathrm{NO}_{2}\right)_{x}$, then it can be shown that

$$
1-i=R+3.2125 f(1-R) .
$$

The corrected value, $f^{\prime}$, of the mass fraction of nitrogen in the nitrocellulose is

$$
f^{\prime}=\frac{f}{1-i} .
$$

The derived values for the heats of combustion and formation of cellulose and nitrocellulose, together with the corrected nitrogen contents, are given in table 3 . The proper values for the heats of formation of gaseous carbon dioxide and liquid water at $30^{\circ} \mathrm{C}$ were taken from reference [19].

It was found that the data on the heats of combustion of the nitrocellulose could be represented by linear equations expressing the heat of combus- tion at $30^{\circ} \mathrm{C}$ as a function of the corrected nitrogen content. The following equations, which were derived by the method of least squares, represent the heats of combustion per gram of nitrocellulose within about 0.03 percent. For nitrocellulose from cotton linters:

$$
\Delta H_{c}^{\circ}=-4169.32+14069 f^{\prime} \mathrm{cal} / \mathrm{g}\left(0.115 \leqq f^{\prime} \leqq 0.135\right) .
$$

For nitrocellulose from wood pulp:

$$
\Delta H_{c}^{\circ}=-4186.36+14200 f^{\prime} \mathrm{cal} / \mathrm{g}\left(0.115 \leqq f^{\prime} \leqq 0.135\right),
$$

where $f^{\prime}$ is the corrected fraction of nitrogen in the nitrocellulose.

TABLE 3. Derived data for cellulose and nitrocellulose

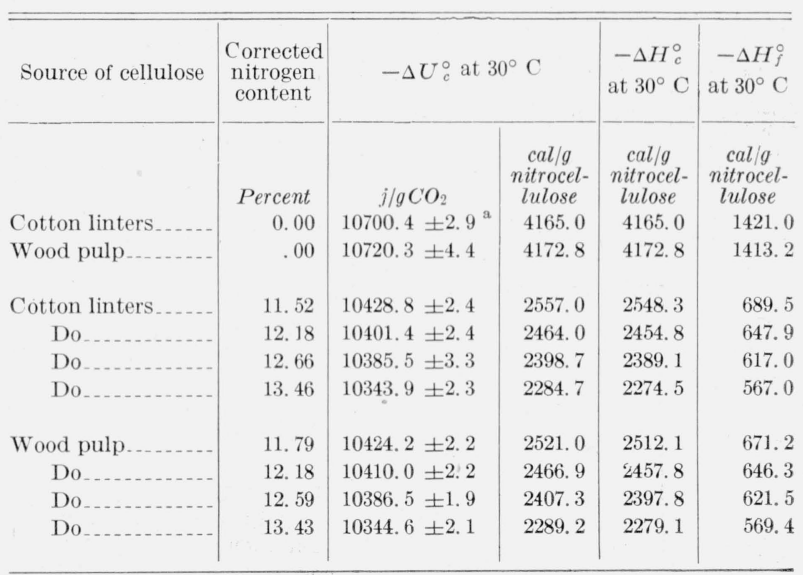

a Standard deviation of the mean. 


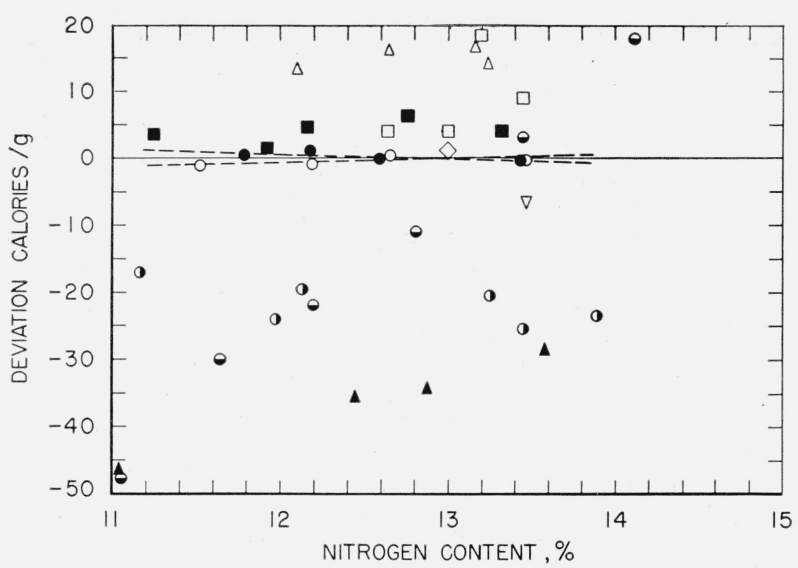

Figure 2. Deviations of values of heat of combustion $\left(--\Delta H_{c}^{\circ}\right)$ derived from results of various observers from eq 3 of the present work.

$\bigcirc$, Present work, nitrocellulose from cotton linters $\left(30^{\circ} \mathrm{C}\right)$; work, nitrocellulose from wood pulp $\left(30^{\circ} \mathrm{C}\right) ; \nabla$, Sarrau and Vieille $\left(15^{\circ} \mathrm{C}\right)$ [11]; $\diamond$, Kast [12]; $\mathbf{\square}$, Muraour [13]; $\boldsymbol{O}$, Prettre $\left(20^{\circ} \mathrm{C}\right)$ [14]; $\boldsymbol{\Delta}$, Kozo Tomioka

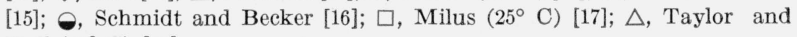
Hall $\left(17^{\circ} \mathrm{C}\right)$ [18].

If we consider all the nitrocelluloses together, the following equation represents the data within about 0.05 percent:

$\Delta H_{c}^{\circ}=-4176.70+14126 f^{\prime} \mathrm{cal} / \mathrm{g}\left(0.115 \leqq f^{\prime} \leqq 0.135\right)$.

Similar equations can be derived expressing $\Delta H f^{\circ}$ at $30^{\circ} \mathrm{C}$ as functions of nitrogen content. Thus the following equation, based on the data on all the nitrocelluloses, represents the values given in table 3 on the nitrocelluloses within about 1.3 $\mathrm{cal} / \mathrm{g}$ :

$\Delta H_{f}^{\circ}=-5896.88+26178 f^{\prime} \mathrm{cal} / \mathrm{g}\left(0.115 \leqq f^{\prime} \leqq 0.135\right)$.

The data on the nitrocelluloses are plotted in figure 2. The abcissa is the nitrogen content of the nitrocellulose, while the ordinate is the devia- tion from the heat of combustion $\Delta H_{\underline{c}}^{\circ}$ given by eq 3. The dotted lines represent eq 1 and 2.

Although there were significant differences between the heats of combustion of cellulose from cotton linters and from wood pulp, 0.18 percent, and between the nitrocelluloses from cotton linters and from wood pulp, maximum 0.1 percent, it is felt that this probably does not indicate a real difference in the heats of combustion of pure cellulose or of nitrocellulose from cotton linters or wood pulp. Rather, the differences are an indication that the impurities in the materials made some contribution to the heat of combustion.

It will be noted that the nitrogen contents of the nitrocelluloses investigated are all intermediate between the nitrogen contents of dinitrocellulose, $f^{\prime}=0.1111$, and trinitrocellulose, $f^{\prime}=0.1414$. The values for the heats of combustion and formation of dinitrocellulose and trinitrocellulose ${ }^{3}$ calculated by substitution of $f^{\prime}=0.1111$ and $f^{\prime}=0.1414$ into eq 1 and 2, and the corresponding equations for heat of formation, are given in table 4 along with the values for the celluloses.

\section{Results of Previous Measurements}

Measurements of heats of combustion or heats of explosion of nitrocelluloses have been reported by Sarrau and Vieille [11], Kast [12], Muraour [13], Prettre [14], Tomioka [15], Schmidt and Becker [16], Milus [17], and Taylor and Hall [18]. In figure 2 the results of various investigators are compared. The values of $-\Delta H_{c}^{\circ}$ attributed to previous investigators were derived as follows:

\footnotetext{
3 It is of interest to compare the data on cellulose and nitrocellulose with similar data on ethanol and ethyl nitrate. The differences between the heats of formation of cellulose and nitrocellulose range from 24.4 to $25.0 \mathrm{kcal}$ per nitrate group. The corresponding difference between the heats of formation of liquid ethanol and liquid ethyl nitrate (reference [19], tables 23-29 and $23-45(1948)$ ) is $22.1 \mathrm{kcal}$. Combination of the latter value with an accurate value for the heat of formation of cellulose would, therefore, have yielded values for the heats of formation of dinitrocellulose and trinitrocellulose in error by about 5 and $7.5 \mathrm{kcal}$ per monomer unit, respectively.
}

TABLE 4. Heats of combustion and formation of cellulose, dinitrocellulose, and trinitrocellulose

\begin{tabular}{|c|c|c|c|c|c|c|c|}
\hline Material & Source of cellulose & \multicolumn{2}{|c|}{$-\Delta U_{e}^{\circ}$ at $30^{\circ} \mathrm{C}$} & \multicolumn{2}{|c|}{$-\Delta H_{e}^{\circ}$ at $30^{\circ} \mathrm{C}$} & \multicolumn{2}{|c|}{$-\Delta H_{f}^{\circ}$ at $30^{\circ} \mathrm{C}$} \\
\hline Dellulose & $\begin{array}{l}\left\{\begin{array}{l}\text { Cotton linters } \\
\text { Wood pulp }\end{array}\right. \\
\left\{\begin{array}{l}\text { Cotton linters } \\
\text { Wood pulp } \\
\text { Cotton linters } \\
\text { Wood pulp }\end{array}\right.\end{array}$ & $\begin{array}{c}c a l / g \\
4165.0 \\
4172.8 \\
2614.4 \\
2616.9 \\
2190.2 \\
2188.7\end{array}$ & $\begin{array}{c}\text { kcal/monomer } \\
\text { unit } \\
675.3 \\
676.6 \\
659.2 \\
659.8 \\
650.8 \\
650.4\end{array}$ & $\begin{array}{c}\text { cal./g } \\
4165.0 \\
4172.8 \\
2606.0 \\
2608.6 \\
2179.5 \\
2178.1\end{array}$ & $\begin{array}{c}k c a l / \text { monomer } \\
\text { unit } \\
675.3 \\
676.6 \\
657.1 \\
657.7 \\
647.6 \\
647.2\end{array}$ & $\begin{array}{r}c \text { cal/g } \\
1421.0 \\
1413.2 \\
715.3 \\
712.8 \\
523.9 \\
525.4\end{array}$ & $\begin{array}{c}\text { kcal/monomer } \\
\text { unit } \\
230.4 \\
229.2 \\
180.4 \\
179.7 \\
155.7 \\
156.1\end{array}$ \\
\hline
\end{tabular}


Where sufficient data were given, the reported values of heat of combustion or heat of explosion were corrected to the basis of the energy units used in the present work, and for the Washburn effect [8], and, where necessary, were reduced to a constant pressure basis. The resulting values were then combined with values for heats of formation [19] of the products of the combustion or explosion reaction to obtain the values of $-\Delta H_{c}^{\circ}$. The various values were not reduced to a common temperature, because no data on the heat capacities of nitrocelluloses have been found. The differences between the results of different observers are so large that the reduction of the results to a common temperature would not improve the agreement to a significant extent.

\section{References}

[1] H. C. Dickinson, Bul. BS 11, 189 (1914) S230.

[2] R. S. Jessup and C. B. Green, J. Research NBS 13, 496 (1934) RP721.

[3] R. S. Jessup, J. Research NBS $\mathbf{2 9}, 247$ (1942) RP1499.
[4] F. D. Rossini, Chem. Rev. 18, 233 (1936).

[5] F. D. Rossini and W. E. Deming, J. Wash. Acad. Sci. 29, 416 (1939).

[6] R. S. Jessup, J. Research NBS 21, 475 (1938) RP1140.

[7] J. R. Katz, Proc. Roy. Soc. Amsterdam 13 II, 958 (1911).

[8] E. W. Washburn, BS J. Research 10, 525 (1933) RP546.

[9] R. S. Jessup, J. Research NBS 36, 421 (1946) RP1711.

[10] NBS Circular C475, p. 22 (1949).

[11] Sarrau and Vieille, Compt. rend. 93, 269 (1881).

[12] H. Kast, Spreng- und Zündstoffe p. 71 (1921). Data taken from reference [15].

[13] Muraour, Data taken from reference [15].

[14] M. Prettre, Mem. Poudres 24, 223 (1931).

[15] K. Tomioka, J. Cellulose Inst., Tokyo 8, 88 (1932).

[16] A. Schmidt and F. Becker, Z. ges. Schiess-u. Sprengstoffw. 28, 280 (1933).

[17] P. R. Milus, Ind. Eng. Chem. 29, 492 (1937).

[18] J. Taylor and C. R. L. Hall, J. Phys. Chem. 51, 593 (1937).

[19] Selected values of chemical thermodynamic properties, National Bureau of Standards, Washington, D. C., Series I, Volume I, Tables 8-1 (1947) and 23-2 (1948).

Washington, December 14, 1949. 